\title{
Comparing the steady state results of a range of multispecies models between and across geographical areas by the use of the jacobian matrix of yield on fishing mortality rate
}

\author{
John G. Pope ${ }^{\mathrm{a}, *}$, Valerio Bartolino ${ }^{\mathrm{b}}$, Nataliia Kulatska ${ }^{\mathrm{b}}$, Barbara Bauer ${ }^{\mathrm{c}}$, Jan Horbowy ${ }^{\mathrm{d}}$, \\ Joana P.C. Ribeiro ${ }^{e}$, Erla Sturludottir ${ }^{\mathrm{e}}$, Robert Thorpe ${ }^{\mathrm{f}}$ \\ ${ }^{\text {a }}$ NRC (Europe) Ltd., UK \\ b Swedish University of Agricultural Sciences, Department of Aquatic Resources, Sweden \\ ${ }^{\mathrm{c}}$ Baltic Sea Centre, Stockholm University, Sweden \\ d National Marine Fisheries Research Institute, Poland \\ e Science Institution, University of Iceland, Iceland \\ ${ }^{\mathrm{f}}$ Cefas, UK
}

\section{A R T I C L E I N F O}

Handled by A.E. Punt

Keywords:

Comparing multispecies models

North Sea

Baltic Sea

Icelandic waters

EBFM

Jacobian

\begin{abstract}
A B S T R A C T
Like other fisheries models, multispecies models are subject to various sources of error. However, with regard to their use for ecosystem-based fisheries management (EBFM) between model errors are likely to be most important. As multispecies models are by definition many-dimensional, comparing them is potentially a complex task. The paper uses a simple approach. This is to calculate the Jacobian matrix of long term steady state catch by species with respect to the fishing mortality relative to status quo levels on all species. This enables the comparison of the relative strength of species interactions among models both within and between regions. This Jacobian matrix approach to comparing multispecies models is applied to available models for the North Sea, the Baltic Sea and from Icelandic waters. Moreover, this information is used to provide the basis for estimating a multidimensional quadratic yield surface for each model in the near field. Used this way it is possible to compare different model estimations of fishing mortality rate changes needed to approach yield-related management goals. The results suggest considerable variation between models in their detailed results but more coherence in suggesting directions for changing fishing mortality rate. Thus the approach is of considerable importance in specifying the confidence with which it is possible to make multispecies predictions for EBFM.
\end{abstract}

\section{Introduction}

Multispecies models in fisheries ecology were originally conceived to account for the between species interactions and feedbacks that are ignored by single species models. These effects become especially relevant when stock sizes of predators and prey change in the longer term, for example in response to management initiatives or environmental change. Thus, Pope (1991) suggested that while single species models are often adequate for short term predictions they are very likely misleading for long term predictions. Consequently one of the important roles of multispecies models could be to make predictions on how long term yields will be affected by specific management measures. This role has become increasingly important with the commitment of policy towards ecosystem-based fisheries management (EBFM). In contrast to traditional fisheries management that considers single species mostly in isolation, one of the key principles of EBFM is managing fisheries as part of an ecosystem. However, multispecies models may only play an operative role in fisheries management if scientists develop methods to test model behaviour and ultimately to ensure that multispecies models consistently account for interactions and feedbacks.

Multispecies models differ in their structures and approaches to measuring interactions and feedbacks; for example some are top down models focused on predation mortality while others are bottom up models focused on food transfers. As a consequence it is likely that variation between models may be the largest cause of variation in their predictions. Comparing the consistency of different models' results within systems is the obvious first step to understanding this problem. Potentially comparisons across systems might also be helpful. Such comparisons were one of the objectives of the EU Framework 7 funded

\footnotetext{
* Corresponding author at: NRC (Europe) Ltd., The Old Rectory, Staithe Road, Burgh St. Peter, Beccles, Suffolk, NR34 0BT, UK.

E-mail address: popejg@aol.com (J.G. Pope).
} 
MareFrame project that is the focus of this special issue.

Making comparisons of multispecies models is a complex problem because of their multidimensional nature. Hence, in making comparisons between models it is wise to concentrate on one aspect of the problem. Previous attempts to compare include Plagányi (2007), Whipple et al. (2000) and Nielsen et al. (2017) who focused on categorizing models based on their structure, capabilities and implementation for management. Hill et al. (2007) reviewed how to deal with structural differences among models in the context of fisheries management, e.g. with contrasting advice and model weighting. A number of papers (e.g. Forrest et al., 2015; Fulton and Smith, 2004; Kaplan et al., 2013; Smith et al., 2011, 2015; Tittensor et al., 2018) compared the results of simulated management strategies in various models. Gårdmark et al. (2013) estimated model uncertainty in terms of predicted climate change effects on the population of eastern Baltic cod. Comparisons in all of these studies were either qualitative, or focused on quantitative differences in model predictions in certain indicators under various scenarios, but did not include a systematic, mathematical analysis of the extent that differences in model structure affect certain aspects of modelled system behaviour. One notable exception is the work of Essington (2004) who compared the F-yield relationship in multispecies statistical and process-based models under various model assumptions on trophic relationships.

This paper focuses on specific results of nine different realisations of multispecies models in three separate areas, the North Sea, the Baltic Sea and Icelandic waters. In particular it focuses on how the fishing mortality rate on each species affects both the yield of that species and of other species (or species groups) in the system. This effect might be by reducing predation if it is a predator or by reducing or changing the focus of the food of predators if it is a prey species. It is important to be clear that the comparisons are purely on the species interactions shown by the models and do not include any mixed fishery effects. By-catches are certainly an important issue for many fisheries but here it is best to keep the comparisons as simple as possible to isolate species interaction as a potential cause of divergence between models. Thus fishing mortality rates are applied separately to each species.

We compare model behaviour within each system by using a novel Jacobian matrix approximation approach. By definition ${ }^{1}$ "a Jacobian matrix is the matrix of all first-order partial derivatives of a vectorvalued function". In our case this function is the vector of long term steady state yield at status quo fishing levels of each of the species in the model. Its Jacobian is then the matrix of partial derivatives with respect to proportionate changes in fishing mortality rate on each of the species from status quo levels. We argue that the use of the Jacobian matrix could represent a simple and valuable approach to improve our understanding of multispecies models by reducing their complexity while maintaining the essential information on the direct effect of fishing and on the indirect effects via species interactions. In simple words the Jacobian shows: - Firstly, the rate of increase or decrease of the long term steady state yield of a particular species in relation to proportional changes in the fishing mortality rate on that species: - Secondly, its rate of increase or decrease related to the proportional changes in the fishing mortality rate of other species. The first effect is the direct effect of fishing on the species while the second group of changes are the multispecies effects. These multispecies changes come about because fishing on other species affects the sizes of populations of the predators, prey and perhaps of the alternative prey of the predators of the species in question. Note that fishing mortality rates of any species have only indirect effects on other species, as mixed fisheries effects are excluded.

The Jacobian matrix cannot be calculated analytically for complex multispecies models. However, in principle it can be approximated numerically by running models to long term steady state with each

\footnotetext{
${ }^{1}$ Definition from Wikipedia https://en.wikipedia.org/wiki/ Jacobian_matrix_and_determinant\#Jacobian_matrix
}

species fishing mortality rate $F(j)$ increased in turn from status quo levels by an infinitesimally small proportion and observing the resulting small changes in yield of each species in the model. In practice, small, but finite changes in fishing mortalities (e.g. 10\%) are better used to avoid rounding errors. We then can approximate the yield surface of each species in the vicinity of the long term steady state with respect to status quo mortalities by a quadratic equation. The partial derivatives of this equation can then be used to directly estimate each element of the Jacobian matrix. Using a quadratic equation to summarise the behaviour of more complex multispecies models was suggested by Pope (1991), and Collie et al. (2003) shows an example of such an approximate model.

In addition to its use in estimating the Jacobian matrix, we can use this simple model to directly see which the most important interactions are. It may also be used to judge the balance of single species compared to multispecies interactions both to the yield of each species and to the overall yield of the system. Following Collie et al. (2003) it is also possible to use the approximate quadratic equation as a very simple multispecies model of how the steady state yield of all species will change, at least in the near vicinity to the status quo steady state. Although in practice this model may be no more than locally valid it is of considerable help in understanding the behaviour of more complex models. It can be used to emulate the behaviour of the complex model's output of long term yield predictions close to the status quo levels of fishing mortality rate. This may be useful as an interactive communication or educational tool presented to stakeholders, where fishing mortalities can be optimized without the need to make many runs of slower more complex and less mathematically tractable models (e.g. Collie et al., 2003).

Used in this fashion, this approach provides a standardised methodology to compare predictions from different models on the direction of changes in fishing mortality rate on each species compared to status quo that would improve yields of individual fisheries or the whole system. Since one of the likely uses of multispecies models in EBFM is to point out sensible directions of change of the fishing mortality of each species, it is very relevant to estimate if models are giving broadly similar or wildly different advice in this respect. The approximate model parameters can also be used to consider other more complex multispecies reference points which would be otherwise difficult to be computed consistently from different models. This possibility was considered in early work (ICES, 1989) where several multispecies reference points were computed for the North Sea based upon quadratic approximations and the use of linear algebra to identify the various optima.

To summarise, the objectives of this paper are:

Firstly to estimate the parameters of the quadratic equation and the Jacobian matrix for two or more models in each of three geographical areas and to compare the degree of interactions they expose both within and between areas.

Secondly to calculate direction of change that will maximize whole system yield and to compare these estimates within areas.

It should be stressed that we propose the analysis of the Jacobian matrix as merely one model comparison tool among several others. Multispecies models are complex and typically generate extensive and often bewildering outputs that demand the use of an array of complementary tools that all answer different questions (see references above).

\section{Material and methods}

This section describe firstly how the Jacobian matrix will be estimated from each of the model runs in each of the three areas and how this is used to construct the multispecies index. Secondly it describes how the Jacobian matrix is used to estimate the fishing mortality rates that will maximize overall yield for each model in each area subject to constraints that no fishing mortality can change by more than $\pm 25 \%$. 

area.

Thirdly brief descriptions are given for each model utilised in each

\subsection{Estimating quadratic parameters and the elements of the Jacobian} matrix

Each of the models examined provided output tables of the long term steady state yield of each species to be expected at status quo fishing mortalities and how each of these yields are changed when each fishing mortality rate is separately increased by a small percentage (typically by $10 \%$ ). The first task is to use these yield outputs to estimate the elements of the Jacobian matrix. These are then used to estimate a multispecies index for each species to describe how much its biomass is influenced by multispecies effects.

For each of the species (i) in a model define its relative fishing mortality rate as $\Phi_{i}=F_{i} / F(\text { status quo })_{i}$, where $F_{i}$ is its fishing mortality rate. Then define approximate yield $\left(Y_{\dot{ }}\right)$ as

$Y_{i}=\Phi_{i}\left(\alpha_{i}+\sum_{\text {all } j} \beta_{i j} \Phi_{j}\right)$.

The equation is based on the assumption that yield equals fishing mortality multiplied by the average exploitable stock biomass. The latter is proportional to the bracketed part of the right hand side (RHS) of Eq. (1). Exploitable stock biomass can be viewed as the sum of biomass when fishing mortality is zero $\left(\alpha_{i}\right)$ and both positive and negative biomass changes $\left(\beta_{i j}{ }^{*} \Phi_{j}\right)$ due to fishing mortality on any species $j$ in the system. Thus, in the Eq. (1), $\alpha_{i}$ is proportional to the steady state exploitable biomass of species $i$ when there is no fishing on any of the species while the $\beta_{i j}{ }^{*} \Phi_{j}$ are similarly proportional to the amount its biomass would change by (up if $>0$ or down if $<0$ ) for any value of $\Phi_{j}$ the relative fishing mortality rate of species $j$.

To estimate the parameters $\alpha_{i}$ and $\beta_{i j}$ of Eq. (1) for a specific model it is run first with the $\Phi=1$ for all stocks (i.e. at status quo fishing mortality) and then multiple runs are made with each stock in turn having its $\Phi=1.1$ while all other stocks remain at the status quo $\Phi=1$ level. If there are $\mathrm{n}$ stocks in a model this provides a $(\mathrm{n}+1) * \mathrm{n}$ table of $Y_{i}$ at status quo (a $1 * n$ row) and (a $n * n$ matrix) at each stocks 1.1 relatively mortality level. This is just sufficient information to solve for the $\mathrm{n}$ values of $\alpha_{i}$ and the $\mathrm{n} * \mathrm{n}$ values of $\beta_{i j}$. To solve for these we write the model estimates of status quo yield of species $i$ as $Y_{i}(1)$ and the yield of species $i$ when $\Phi_{k}=1.1$ as $Y_{i}(k)$.

Then (recalling that $\Phi=1$ at status quo) Eq. (1) indicates that,

$Y_{i}(1)=\alpha_{i}+\sum_{\text {all } j} \beta_{i j}$

If $k \neq i$ and $\Phi_{k}=1.1$ and all $\Phi_{j}=1$ where $k \neq j$ then Eq. (1) indicates that;

$Y_{i}(k)=\alpha_{i}+\sum_{\text {all } j \neq k} \beta_{i j}+1.1 * \beta_{i k}$

Alternatively if $k=i$ so that $\Phi_{i}=1.1$ and all other $\Phi j=1$ then,

$Y_{i}(i)=1.1 * \alpha_{i}+1.1 * \sum_{\text {all } j \neq i} \beta_{i j}+1.1 * 1.1 * \beta_{i i}$.

Subtracting Eq. (2a) from Eq. (2b) leaves only terms of $Y_{i}(k)$ and $Y_{i}(1)$ on the left hand side (LHS) and only $0.1 * \beta_{i k}$ on the RHS. This then simplified to,

$\beta_{i k}=\left(Y_{i}(k)-Y_{i}(1)\right) / 0.1$, if $\mathrm{i} \neq \mathrm{k}$

This equation can be applied successively to estimate all the $\beta_{i j}$ where $j \neq i$.

Subtracting Eq. (2a)*1.1 from Eq. (2c) leaves only terms of Yi(i)-Yi (1)*1.1 on the LHS and $\left(1.1^{2}-1.1\right) * \beta_{i i}$ on the RHS of the equation which then simplifies to, $\beta_{i i}=\left(Y_{i}(i)-Y_{i}(1) * 1.1\right) / 0.11$,

Having estimated all $\beta_{i j}$ the $\alpha_{i}$ ss may be estimated by subtracting the sum of $\beta_{i j}$ for each species $i$ from $Y_{i}(1)$ (using Eq. (2a)).

These estimates of $\alpha_{i}$ and $B_{i j}$ may then be used to compute the elements of the Jacobian matrix by partial differentiation of Eq. (1) as,

$$
\begin{aligned}
& \frac{\partial Y_{i}}{\partial \Phi_{i}}=\alpha_{i}+\beta_{i i} \Phi_{i}+\sum_{a l l j} \beta_{i j} * \Phi_{j} \\
& \frac{\partial Y_{i}}{\partial \Phi_{j}}=\beta i j \Phi_{i}, \text { where } j \neq I
\end{aligned}
$$

The value of the Jacobians at status quo (when all $\Phi_{j}=1$ ) is thus as Eqs. (3a) and (3b) without the $\Phi \mathrm{s})$.

Notice from Eq. (2a) (where all $\Phi_{j}=1$ ) that the sum of $\alpha_{i}$ and all the $\beta_{i j}$ equals $Y_{i}(1)$ and therefore dividing $\alpha_{i}$ and $\beta_{i j}$ by $Y_{i}(1)$ is a convenient way to standardise them for each stock within each model. Doing this enables these to all be displayed on a comparable scale.

Having estimated the $\alpha_{i}$ and $\beta_{i j}$ for each stock in a model a multispecies index "index(MS)" can be estimated to show how importance multispecies effects are for the species. This is estimated as,

$\operatorname{index}(M S)_{i}=\sum_{\text {all } j \neq i}\left|\beta_{i j}\right| / \sum_{\text {all } j}\left|\beta_{i j}\right|$

Where $\left|\beta_{i j}\right|$ indicates the absolute value of $\beta_{i j}$.

Since this index is constructed only of the $\beta$ terms it is showing how a species' biomass (rather than its yield) responds to advantageous changes in the relative fishing mortality on other species compared its response to changes in its own relative fishing mortality. This index would have a value of zero for species with no multispecies effects and 1 for species with no direct effects of fishing $(\beta i i=0)$ on its biomass.

An additional use for the quadratic parameters is as a model diagnostic tool. Not all values of $\beta_{i j}$ may be plausible and screening for these can prove a useful model diagnostic. An obvious example of an unusual result might be finding a $\beta_{i i}>0.0$ for a species since this would mean its yield for ever increased as its fishing mortality rate increased. There would be reason to examine a model carefully if a $\beta_{i j}<0.0$ for an important predator $j$ of species $i$. There could also be concerns with a case where an $\alpha_{i}<0.0$ since that would indicate a stock that might disappear even with no fishing.

\subsection{Estimating the relative Fishing Mortalities giving a constrained maximum yield}

If it is supposed that Eq. (1) describes the models behaviour at all local values of the yields in the range $0.75<\Phi_{i}<1.25$ then it may be used to describe the relative fishing mortalities that would give the maximum of total yield in this constrained range of the $\Phi_{i}$. This is achieved using the SOLVER function in EXCEL; always starting each optimization with all $\Phi_{j}=1$. The sum of species yield is used as the function to maximize, subject to the constraints that $0.75 \leq \Phi_{i} \leq 1.25$ for all $i$ and that all $Y_{i} \geq 0.0$. The values of relative fishing mortality that give maximum yield in this constrained range then provide an indication of the direction of change likely to increase overall yield. In principle other objectives may also be compared by such an approach.

\subsection{The models}

\subsubsection{North Sea Model 1}

SMS is described in the 2014 report of ICES WGSAM (ICES, 2014a) as follows: "SMS (Lewy and Vinther, 2004) is a stock assessment model including biological interaction estimated from a parameterised size dependent food selection function. The model is formulated and fitted to observations of total catches, survey CPUE and stomach contents for the North Sea. Parameters are estimated by maximum likelihood and the variance/covariance matrix is obtained from the Hessian matrix. In 
the present SMS analysis the following predator and prey stocks were available: predators and prey (cod, whiting, haddock), prey only (herring, sprat, northern and southern sandeel, Norway pout), predator only (saithe), no predator prey interactions (sole and plaice) and 'external predators' (8 seabirds, starry ray, grey gurnard, western mackerel, North Sea mackerel, North Sea horse-mackerel, western horse mackerel, hake, grey seals, harbour porpoise and hake). The population dynamics of all species save those of 'external predators' were estimated within the model. To reflect the current sandeel assessment, the sandeel in the North Sea were divided into two stocks, a southern containing assessment areas 1 and 2 and a northern area containing areas 3, 4, 5 and 7. The development in the combined biomass of the two new stocks closely follows that of the previously estimated total biomass. However, the dynamics of the two stocks differ as does the relative importance of different predators, with fewer predators exerting a substantial effect on natural mortality in southern than northern areas."

SMS is updated regularly and results are available in the ICES WGSAM reports (e.g. ICES, 2018) and the Working Group to be found at SharePoint on the main ICES website (https://community.ices.dk/ ExpertGroups/wgsam/SitePages/HomePage.aspx.)

Steady state results of multiple runs of SMS with fishing mortality varying on each species were kindly made available, M. Vinther pers. comm.

\subsubsection{North Sea Model 2}

The Charmingly Simple Model (CSM) is a time varying extension of the ideas of Pope et al., 2006. The approach is outlined in ICES (2014a). It uses a structure based upon the 0th to 4th moments of species length distributions. In its present formulation it seeks to emulate SMS by first fitting to historic species size moments. The species fitted are, cod, haddock, herring, Norway pout, plaice, saithe, sandeel (as a combined North Sea stock), sole, sprat and whiting. Forward simulations are then made based upon the fitted parameters of the model. Mortality rates from external predators (see SMS above) are introduced by using SMS values. In its present realization it does not yet contain a stock recruitment function and uses average recruitments to predict future steady states. The design concept of CSM is as a very simple and compact model of the North Sea for use to developing insights into the workings of multispecies models.

\subsubsection{North Sea Model 3 (with 2 variants)}

The North Sea LeMans model (length-based multispecies analysis by numerical simulation, Hall et al., 2006) is a fish community model of the North Sea that is structured by size and species. The modelled community is made up of 21 stocks representing over $95 \%$ of the fish biomass, split into size classes of just over $5 \mathrm{~cm}$, such that sprat might be present in 4 or 5 size classes, but cod would be present in all 32 (Thorpe et al., 2015). Individuals progress through length-classes as they grow and mature at a threshold length. Reproduction is described with a hockey-stock spawner-recruit relationship, which determines the number of recruits entering the smallest size class based upon the biomass of mature individuals. Species' dynamics are linked via predation mortality which varies with predator abundance, size, and species preference as defined with a diet matrix. Individuals are also susceptible to residual natural mortality and fishing mortality. Parameterisation and validation of the model ensemble is described in Thorpe et al. (2015), and model equations are presented in Thorpe et al. (2017).

Within this framework, the consequences of parameter uncertainty were assessed by considering a large number of candidate models, with combinations of parameters drawn from ranges spanning data and literature. These candidate models were screened against data to identify plausible models. The screening criteria were i) all species should persist when there is no fishing, and ii) mean predicted SSBs of 10 modeled stocks should match up acceptably with assessments for the period 1990-2010. The model framework has previously been used to look at the North Sea mixed fishery (Thorpe et al., 2016) and the application of "pretty good yield" (PGY) ranges to the North Sea (Hilborn, 2010; Kempf et al., 2016; Thorpe et al., 2017).

Results shown are from two distinct but acceptable members of the ensemble (E129 and E107) that are viewed as model run 3 and model run 4 for the North Sea.

\subsubsection{Baltic Sea Model 1}

The Gadget implementation in the Baltic is a multispecies, multifleet, single area model representing the temporal development of the age-length structure of the eastern Baltic cod, central Baltic herring and Baltic sprat populations (see Kulatska et al., 2018, for more details on the model). The model includes an active and a passive fishery targeting cod and a pelagic fishery catching sprat and herring. The three fish populations are also affected in the model by grey seal predation which intensity is a simple linear relationship of given seal population size. In the model, both clupeids are removed by cod predation. Three static prey fields are added to the pool of species eaten by cod in the model, such as the two benthic invertebrates Saduria entomon and Mysidae, and a generic other food category. The predator-prey interaction is regulated in the model by three main aspects: (1) the consumption which defines the amount of biomass required by cod during its ontogeny (Jones, 1978), (2) the prey preference which relates the prey species composition in the modelled diet to the prey species composition observed in the cod stomachs, (3) the predator-prey size selection which describes how the size preference for preys of different size changes as the predator grows. The model has a quarterly time step resolution running from 1974 to 2013. The model uses multiple data sets including catch data (ICES, 2016c; STECF, 2014), scientific survey data from both acoustic, pelagic and bottom trawling (ICES, 2016a) and cod stomach data (ICES, 2014b).

\subsubsection{Baltic Sea Model 2}

The multispecies delay-difference production model (MSPM; Horbowy, 1996, 2005) was implemented in components describing adult fish (age 3 and older for cod, and age 2 and older for herring and sprat), young fish (considered unexploited, age 1-2 for cod, and age 0-1 for herring and sprat), and "other food" component, considered constant. Adult cod eats everything in the system; young cod feeds on sprat, young herring, and "other food". The fishery is on top of this system and exploits adult cod, herring, and sprat. Growth parameters (anabolism and catabolism rates) are explicitly included in the model. Predation mortality depends on biomass of predators, and available food, weighted by suitability coefficients.

In classical production models fish growth is assumed constant. In the Baltic, growth of three main species (cod, herring, and sprat) has shown marked declines during three recent decades; as a consequence the weight at age of these species in recent years has been about $40-60 \%$ lower than in the 1980 s and beginning of the 1990s. The growth changes for cod and herring are relatively well explained by area of hypoxic waters and salinity, respectively. In the case of sprat density dependence in growth was demonstrated (Horbowy and Swinder, 1989; Casini et al., 2011). The above dependencies were implemented into MSPM by relating anabolism rate to area of hypoxic waters, salinity, and stock-density, respectively for cod, herring, and sprat.

The model was fitted to catches and stomach contents data, covering 1982-2013. Recruitment to the unexploited component of the stock was implemented as recruitment estimated in ICES analytical assessments scaled by parameter estimated in the model.

\subsubsection{Baltic Sea Model 3}

The Ecopath with Ecosim (Walters et al., 1997; Christensen and Walters, 2004) model of the central Baltic Sea simulates trophic interactions within major components of the offshore food web, from phytoplankton to grey seals, using differential equations. It includes the 
four most important commercial fish species in the offshore Baltic Sea: cod, herring, sprat and flounder (Platichthys flesus), each represented in the model as juvenile and adult age groups. For comparability with other models, flounder is omitted from the Jacobian analysis here. Initial conditions are set to be representative of the year 2004. ICES catch and survey time series from 2004 to 2013 were used for model fitting. More details about the model are found in Bauer et al. (2018) and ICES (2016b).

\subsubsection{Icelandic Waters Model 1}

The Atlantis modelling framework (Fulton et al., 2011; Audzijonyte et al., 2017a, b) was used to construct an end-to-end model of Icelandic waters (Sturludottir et al., 2018). The modelled area is 1.6 million $\mathrm{km}^{2}$ and has been divided into 51 spatial boxes and each box into vertical layers. The model has an underlying oceanographic model of temperature, salinity, and water fluxes from 1948 to 2012. There are 52 functional groups in the model: 20 fish groups (where 8 are at a species level), 5 groups of mammals, 1 seabird group, 16 invertebrates, 5 primary producers, 2 bacteria and 3 detritus groups. The vertebrate groups have up to ten age classes and recruitment and consumption are modelled with Beverton-Holt and Holling type II relationships respectively. The most important commercial fish species are harvested in the model. Each group is harvested by a certain fishing gear which has a selectivity based on length. There are no interactions between the fishing gears. The model was originally run from 1948 to 2012 and calibrated to data from the Marine and Freshwater Research Institute.

\subsubsection{Iceland Waters Model 2}

The Ecopath with Ecosim (EwE) modelling suite (Christensen and Pauly, 1992; Walters et al., 1997; Pauly et al., 2000; Walters et al., 2000) was used to obtain an overview of the marine food-web in Icelandic waters. The model spanned over the Icelandic Exclusive Economic Zone (EEZ), which covers an area of $758000 \mathrm{~km}^{2}$. There were 35 functional groups in the EwE model for Icelandic waters. The functional groups were organized in either single-species or multi-species groups, according to environmental and/or economic importance and available data. The functional groups included: 1 seabird group, 4 groups of marine mammals, 19 fish groups, 9 invertebrate groups, 1 phytoplankton group and 1 detritus group. Of the fish groups, 6 were organized in 2 age classes. The commercial species were harvested in the model, each having an assigned fishing fleet. Ecosim was fitted to a time-series of biomass values, landings, fishing mortality and average annual temperature made available by the Marine and Freshwater Research Institute. Temperature was used as a forcing function of primary production and an anomaly search using 10 spline points was conducted when fitting the model to the time-series. While fitting the model to the time-series, a vulnerability search was also performed, freeing the vulnerability parameters of the groups with time series from their default values to better replicate the trophic dynamics in the ecosystem. Ecosim was originally run over a 30-year period, from 1984 to 2014 .

\section{Results}

\subsection{Comparisons within areas based upon the parameters, Jacobians and multispecies indices}

Fig. 1 shows quadratic equation parameters $\alpha_{i}$ and the $\beta_{i j}$ and the principle Jacobian components for each of the 10 species common to the SMS and CSM models and of two ensemble model members (E129 and E107). The sub-plots show the estimate of $\alpha_{i}$ and the $\beta_{i j}$ of each species $j$ affecting each species $i$. These results are standardized to sum to 1 by dividing by status quo yield of species $i$. The $\alpha$ 's are shown only as being a building block of the direct effect Jacobian values. The $\beta_{i j}(j \neq i)$ are the Jacobian values for the between species interactions and, given the standardization, these indicate how yield would change relative to status quo yield for a change in $\Phi_{j}$ (the relative fishing mortality) rate on species $j$. The $\beta_{i i}$ are not Jacobians and this is indicated by a diagonal box in the figure. The Jacobian results for each species $i$ are shown in the final columns of each subplot. These indicate how species $i$ reacts to changes in $\Phi_{i}$ (its own relative fishing mortality rate). Thus when it is positive, yield would be expected to increase with an increase in its fishing mortality rate, while it would be expected to decrease with a negative Jacobian. Similarly positive or negative $\beta_{i j}$ indicate how it should be expected to respond to increases or decreases in the fishing mortality rate of each species $j$. The plot indicates that most of the multispecies Jacobian terms are too small to be visible. However there is a fairly consistent effect from saithe in the SMS model and from plaice in the E107 model run and cod affects haddock and whiting in SMS runs. Sprat in the E129 and E107 model runs is the only prey species whose removal causes noticeable negative effects. These are on herring, plaice and whiting. The principle Jacobians are of consistent positive direction for cod, haddock, Norway pout, sandeel and sprat in all models but results are variable between models for herring, plaice, saithe, sole and whiting. Numerical values of the Fig. 1 entries are shown in Annex A, Table A1 of the on-line version.

Fig. 2 shows equivalent plots to Fig. 1 for the three species cod, herring and sprat for each of the EwE, Production and Gadget models available for the Baltic Sea. All three models show weak (sprat in EwE) or slight (in the other models) multispecies effects on cod and somewhat stronger but inconsistent effects of cod on herring and sprat. The Jacobians of each species $i$ with its own relative fishing mortality $\Phi_{i}$ are shown and are of consistent direction among the models except for the Gadget result on cod. Numerical values of the Fig. 2 entries are shown in Annex A, Table A2 of the on-line version.

Fig. 3 shows equivalent plots to Fig. 1 for the 10 commercial species groups common to the Atlantis and EwE models available for Icelandic Waters. These show rather more significant multispecies Jacobians than seen in the other two areas. This is particularly the case with the EwE model with the demersal commercial complex, flatfish, Greenland halibut and other cod all being markedly affected by fishing on other species such as herring and saithe. It is also important to note that yields of haddock and other cod were predicted to collapse with this realisation of the EwE model. For Atlantis the most important multispecies interactions occur with saithe fishing that has a positive impact on flatfish, haddock, other cod but a negative impact on herring. As with the other areas there is little correspondence between the detailed interactions seen in the two models and this again is likely due to differences in model structure or parameterization. There is agreement between models here on the direction of the single species Jacobian (that with a species own fishing mortality rate, shown in the last columns of Fig. 3) for 6 species. Capelin, demersal-commercial, flatfish, herring, redfish and saithe have common directions for these Jacobian values while cod, Greenland halibut, haddock and other cod show opposite responses to increasing their own fishing mortality. However, since the last two of these species collapsed at status quo fishing in the EwE model comparisons of these single species Jacobians with the Atlantis model may not have much meaning. Numerical values of the Fig. 3 entries are shown in Annex A, Table A3 of the on-line version.

Figs. 4-6 show the multispecies indices for each area. These summarise differences between models within each area in the way they respond to multispecies as opposed to single species $\beta$ effects. It thus indicates how much each species biomass (rather than its yield) responds to fishing on other species relative to its response to directed fishing. In the North Sea (Fig. 4) it is again apparent that SMS and CSM treat plaice, saithe and sole as single species assessments while E129 and E107 allow multispecies interactions to occur for these species. For the other species multispecies interactions exist for all species but the size of the indices vary considerably across the 4 models. In this area there is no consistent pattern of one model having stronger indices on all species.

For the Baltic sea Fig. 5 indicates that the Gadget model treats cod as a single species stock which is to be expected since no bottom-up effects of 


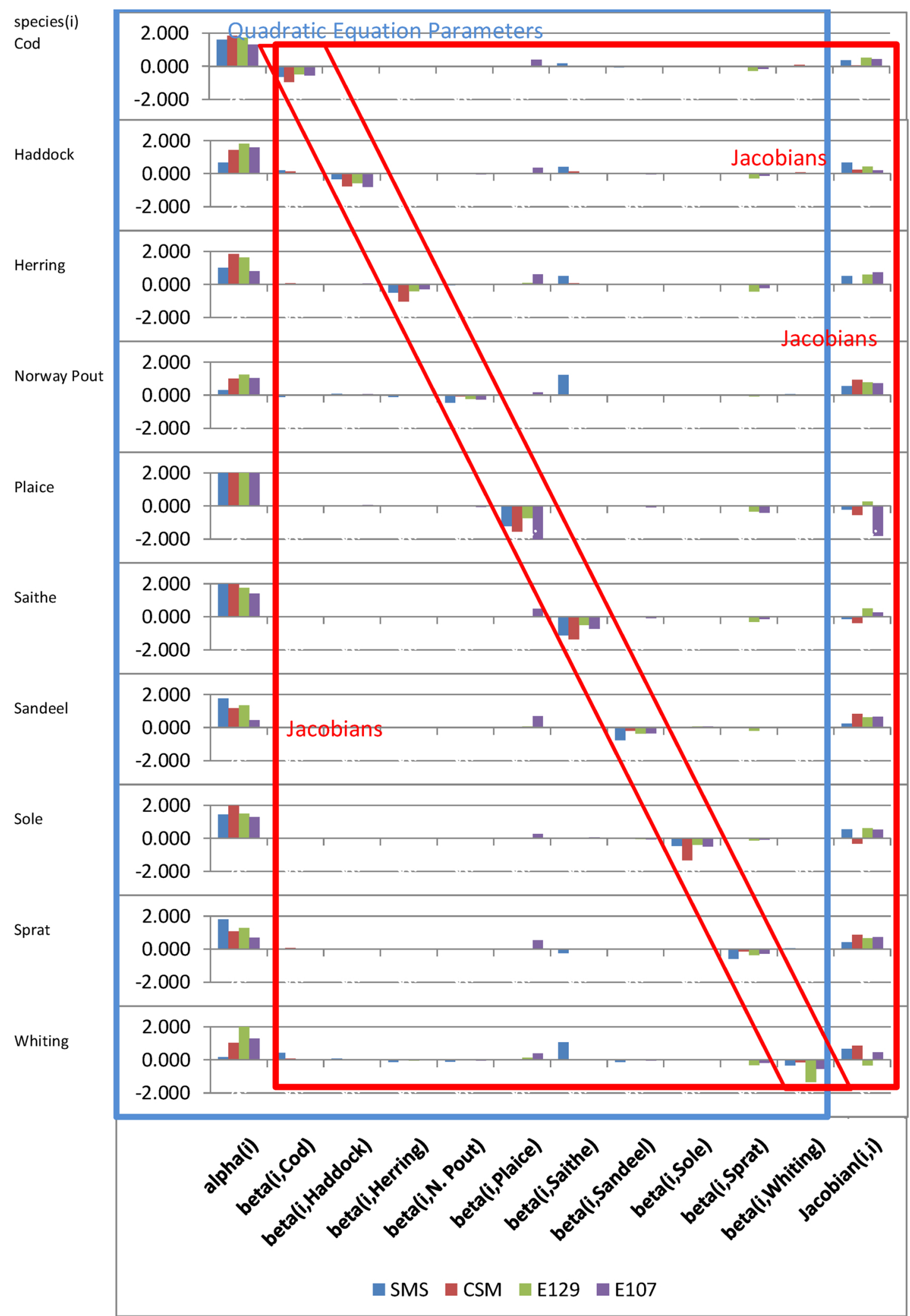

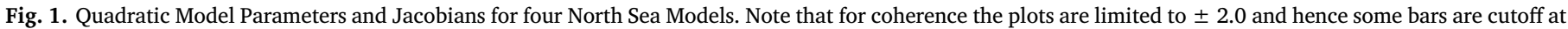
that level. Exact numerical values of all North Sea scaled quadratic parameters and Jacobians may be found in Annex A Table 1 of the on-line version.

clupeids on cod are included in the current model implementation. It is also noticeable that the multispecies indices are always lower for the production model. The Gadget and EwE produce stronger multispecies indices on the pelagic stocks particularly on herring.

For Icelandic waters Fig. 6 shows equivalent results. The two models broadly agree on the high multispecies indices for capelin, flatfish, herring and redfish. Indices for the EwE model particularly suggest the biomasses of all species (except haddock that collapsed at status quo fishing) are more modified by fishing on other species than by their own species based fishing mortality rates. As in the other areas results for 


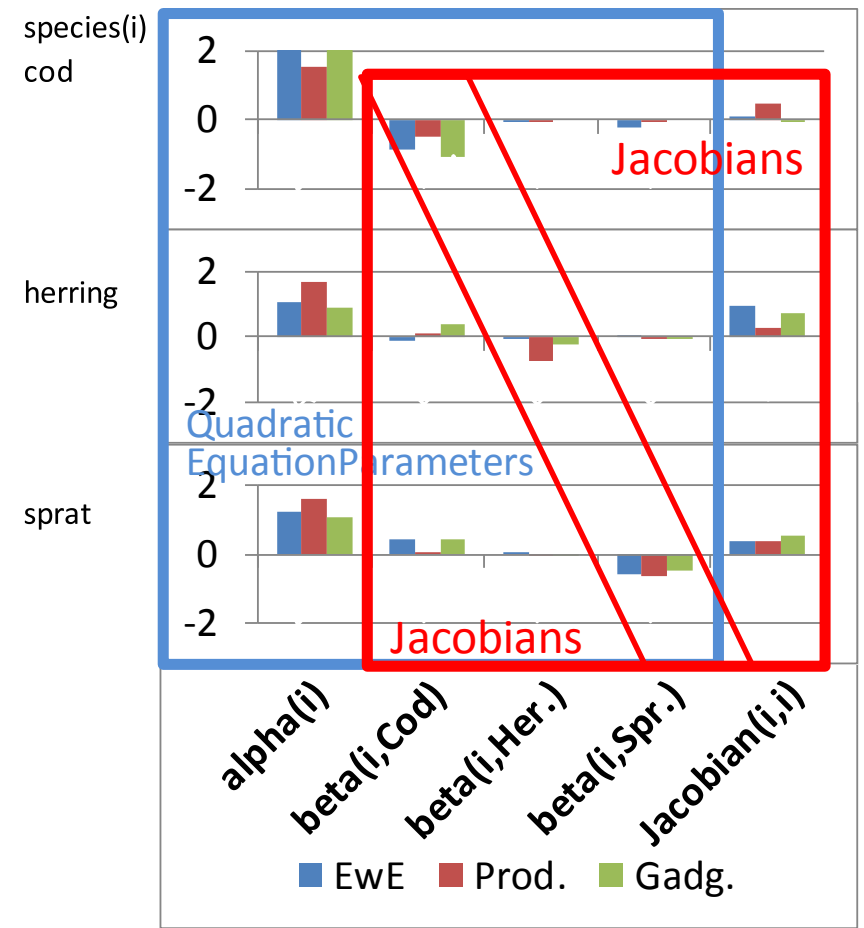

Fig. 2. Quadratic Model Parameters and Jacobians for three Baltic Sea Models. Note that for coherence the plots are limited to \pm 2.0 and hence some bars are cutoff at that level. Exact numerical values of all Baltic Sea scaled quadratic parameters and Jacobians may be found in Annex A Table 2 of the on-line version.

other species show little coherence in these indices.

\subsection{Estimates of the relative Fishing Mortalities giving a constrained maximum yield}

Fig. 7 shows, for the North Sea, the percentage change in fishing mortality rate for each species needed to give the maximum joint yield for each model, with fishing mortality rate held between $75 \%$ and $125 \%$ of the status quo fishing mortality rate for each species. These changes are compared across the 4 North Sea model runs. If overall yield maximization was the objective then for most species in each of the models the full allowed increase of $25 \%$ is indicated. With this objective SMS only advocates dropping mortality rate on Plaice, CSM advocates holding mortality at status quo for herring and dropping mortality on plaice, saithe and sole, E129 drops mortality on sole and on sprat and E107 only on sprat. Thus for cod, haddock, Norway pout, sandeel and whiting all models suggest at least the same direction of change to achieve an overall yield objective.

Fig. 8 shows, for the Baltic Sea, the percentage change in fishing mortality rate for each species needed to give the maximum joint yield for each model, when fishing mortality rate is held between $75 \%$ and $125 \%$ of the status quo fishing mortality rate for each species. The results are rather consistent across the three models. If overall yield maximization was the objective, then all the models advocate increasing cod fishing mortality by the maximum $25 \%$ and increasing fishing mortality rate for the pelagic species. Only the production model suggests increases on the pelagic species should be less than the full $25 \%$ allowed.

Fig. 9 shows, for Icelandic waters, the percentage change in fishing mortality rate for each species needed to give the maximum joint yield for each model, when fishing mortality rate is held between $75 \%$ and $125 \%$ of the status quo fishing mortality rate for each species. As was the case in other areas this suggests that if overall yield was the objective this would be maximised by increasing fishing mortality rates on most species. The figure shows that to achieve this objective 16 out of 20 model*species combinations would require fishing mortality rates to be increase by the full $25 \%$ allowed. Only three would be decreased by the full amount, haddock for both models and other cod for EwE. To maximize overall yield would also require cod fishing mortality rate to remain virtually unchanged with the Atlantis model.

\section{Discussion and conclusions}

\subsection{Model consistency in the strength of multispecies effects within areas}

The quadratic equation parameters and the principle Jacobians provide a useful means of examining the relative importance of species interaction in each model. In general they indicate substantial differences estimates of specific interactions in the different models in an area. This arises in part from the different ways that the different models deal with species interactions.

For example, for the North Sea (Fig. 1) all the models have 10 species in common. However of these models SMS and CSM1 have a limited set of predators cod, haddock, saithe and whiting while all species except plaice, saithe and sole act as prey. This is dictated by the available stomach data. However, since E129 and E107 are not constrained by stomach data they can find predation is more widely distributed. Indeed in E107 plaice is seen as an important predator as is apparent from the Jacobians. In SMS and CSM plaice, saithe and sole are modelled as single species for their own dynamics and thus when $j \neq i$ their $\beta_{i j}$ Jacobians are equal to zero which is not the case in E129 or E107 for these species. Saithe acts as an important predator in SMS but not in the other models. Since CSM attempts to emulate SMS it is perhaps odd that their results are not more similar but this is perhaps because CSM currently lacks a stock recruitment (S/R) relationship. Certainly S/R might magnify any stock changes due to predation. Thus it will be interesting to see how an update to CSM compares if a $S / R$ relationship is included. However, despite the clear differences in detail between the models the principle diagonal Jacobian $(i, i)$ terms (shown in the last columns of Fig. 1 agree on 5 occasions on a common direction for advantageous change in each species' own fishing mortality rate. Moreover, in 32 of the possible 40 model*species combinations these point to increasing fishing.

In a similar fashion Fig. 2 shows considerable differences in how the 3 Baltic Sea models deal with species interactions. In particular the Gadget model treats cod as a single species that is unaffected by changes to the other two species. Although the production model actually includes a mechanism by which cod is affected by the availability of herring and sprat (increased availability of clupeids decreases cod cannibalism), for cod this effect is too small to result in perceptible $\beta$ values from herring or sprat. The off diagonal terms also differ in direction for other species, but all models project an increase in sprat with increased fishing on cod due to predatory release. However, as in the case of the North Sea, there was rather more coherence between models seen for the principle Jacobian estimates. All models, except for Gadget on cod, show a similar direction of change for the principle Jacobians which are suggesting the potential for increased species yield with increased fishing.

Model results from Icelandic waters (Fig. 3) also show considerable divergence between model details. Both models have a large number of groups and many of them have little information on e.g. biomass, recruitment processes and diet composition. This could result in the difference observed between the models. The inconsistence in the Jacobians from the two models could also result from what was assumed to be status quo fishing mortality. There was a variation in fishing mortality between years but the fishing mortality in the last year of the historical model run was taken as the status quo. It could be more robust to take an average over the last few years. Also, if the status quo is close to the maximum sustainable yield the models can easily show inconsistent Jacobians. This difference between the models requires further comparisons between these two models to understand what causes these inconsistencies.

In comparing all three area result it is clear from the Jacobians that the present sets of multispecies models are in many cases inconsistent in 


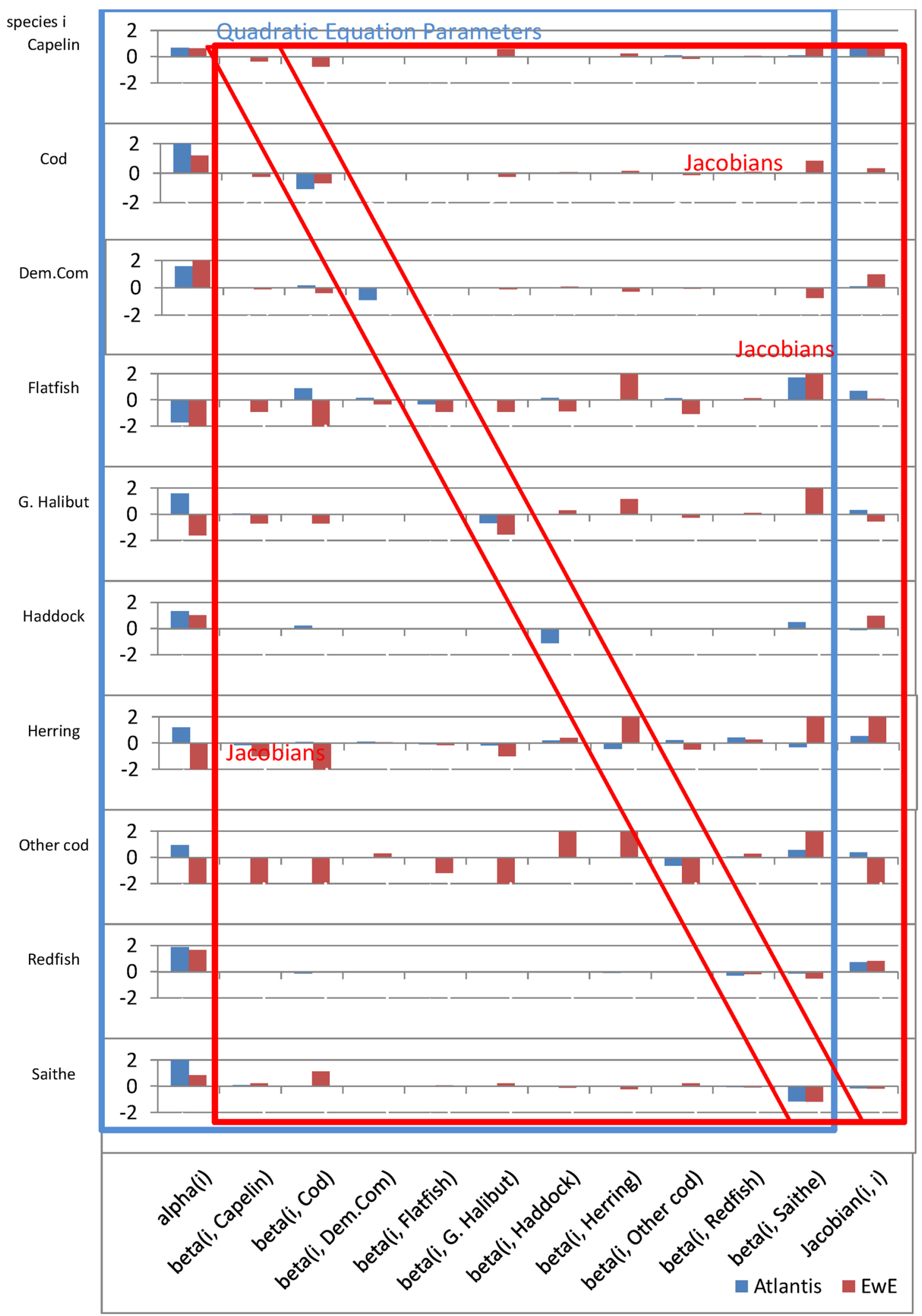

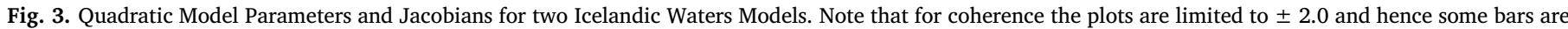

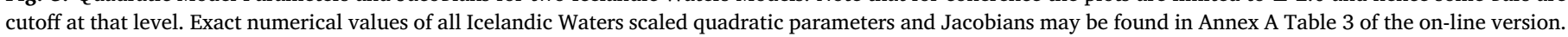

the projected magnitude of one species' yield affected by other species fishing mortality due to trophic interactions. The common reason is that there are considerable differences in the structure of the models, especially regarding how they represent trophic interactions. It is not possible to see any discernible pattern in the overall strength of multispecies interaction between models or species except it is clear when a species dynamics has been treated as being only single species. For all three areas there seems somewhat more coherence between model results in the direction of change indicated by the principle Jacobians. The results from the Multispecies Indices (Figs. 4, 5 and 6) 


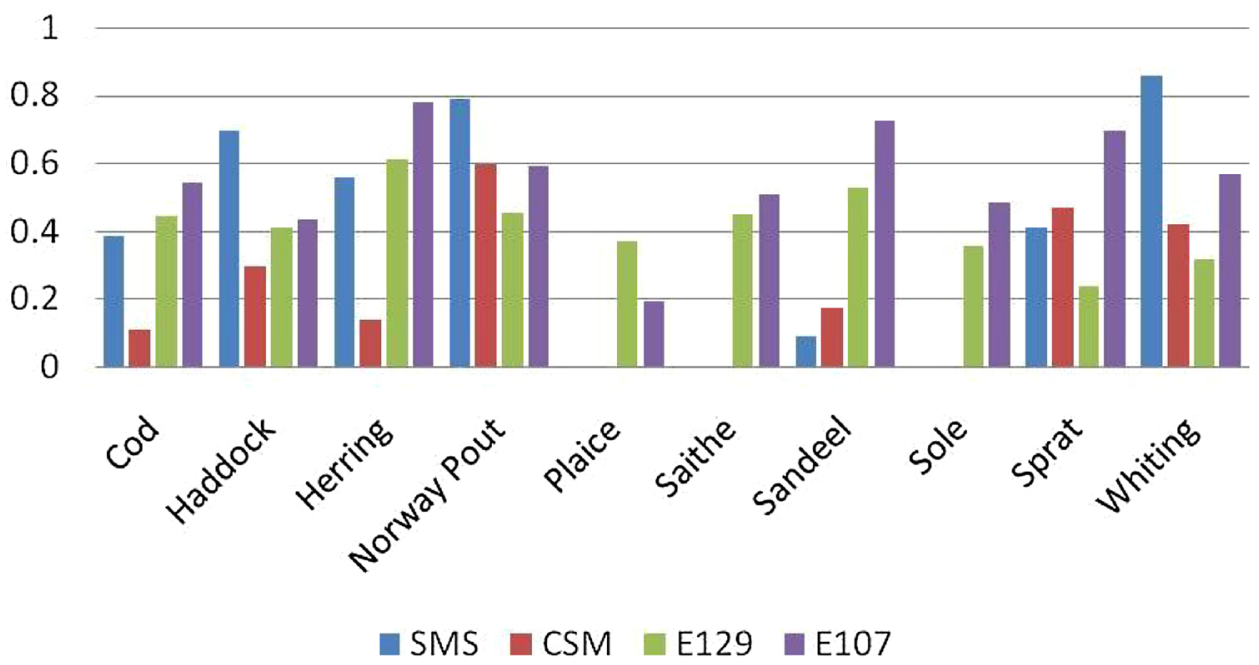

Fig. 4. Multispecies index for each North Sea species for each model.

1

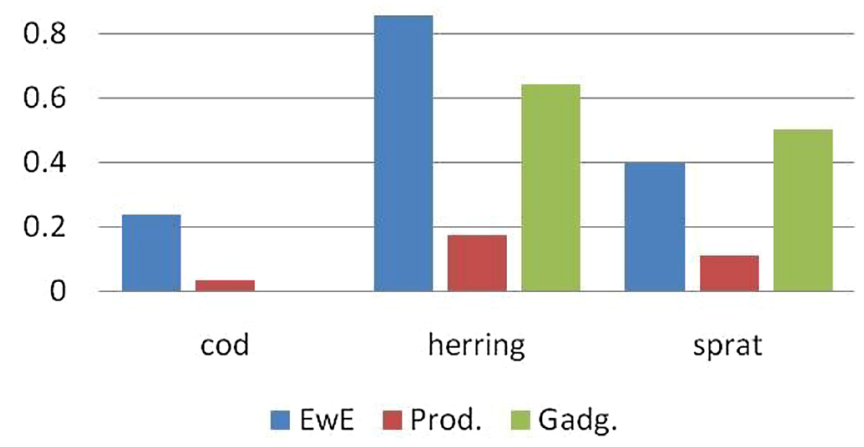

Fig. 5. Multispecies index for each Baltic Sea species for each model.

also indicate that, there are considerable differences in the strength of the aggregate multispecies interactions between species and models.

An additional benefit of calculating the $\alpha_{i}$ and the $\beta_{i j}$ parameters is that they may reveal the form of a species response to changes of its own and other species fishing mortalities in the near field. In particular a positive $\beta_{i i}$ suggests a locally $J$ shaped yield surface. This behaviour was noted for
Icelandic capelin in the Atlantis model and for Icelandic herring in the EWE model. However, in the case of the Atlantis model this seemed a local kink in the capelin yield curve that was overcome by fitting the approximation model over a wider span using the yields at $125 \%$ increases in each $\Phi$ rather than at $110 \%$ as given in equations $2 \mathrm{~b}$ and $2 \mathrm{c}$. The same approach was also used for the Icelandic waters EwE model but a positive $\beta_{i i}$ term persisted for herring and suggests an area for further investigation of the model. These results suggest the possibility of more complex yield surfaces appearing in complex multispecies models, perhaps with several local optima. Such findings do beg to be further investigated. The same is the case when interactions are of opposite direction from what might be suspected from the biology. If there is increased fishing mortality on a predator species the yield of its prey species might be expect to increase. On the other hand, more fishing of any prey of a certain predator might be expected to cause the predator yield to decrease. If opposite results are seen in the Jacobian matrix it poses a question of why this is. In more complex models it is possible such changes might occur due to the effects of various processes, such as competition among alternative prey, predation on juvenile life stages of predatory fish by its prey or competitive or cannibalistic interactions among juvenile and adult life stages of one species. However, asking and answering the simple question posed by values of the Jacobian matrix will help foster a deeper understanding how these complex processes work.

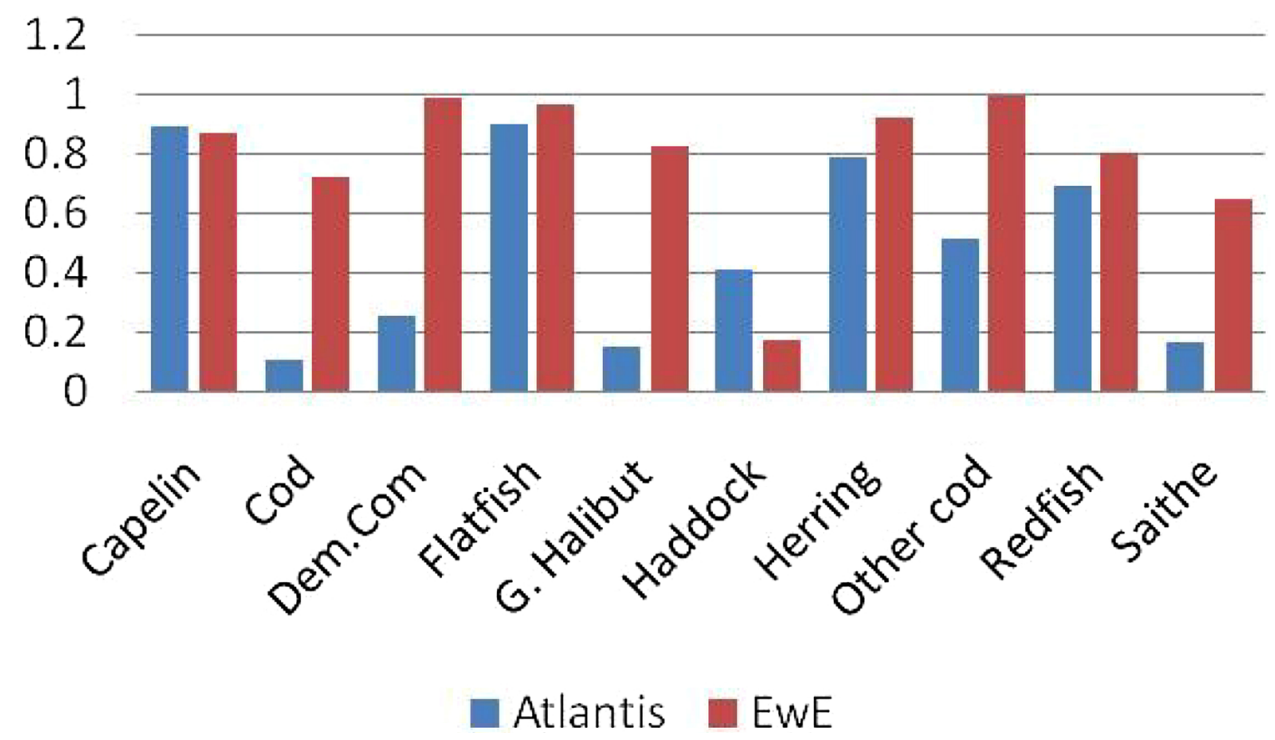

Fig. 6. Multispecies index for each Icelandic species for each model. 


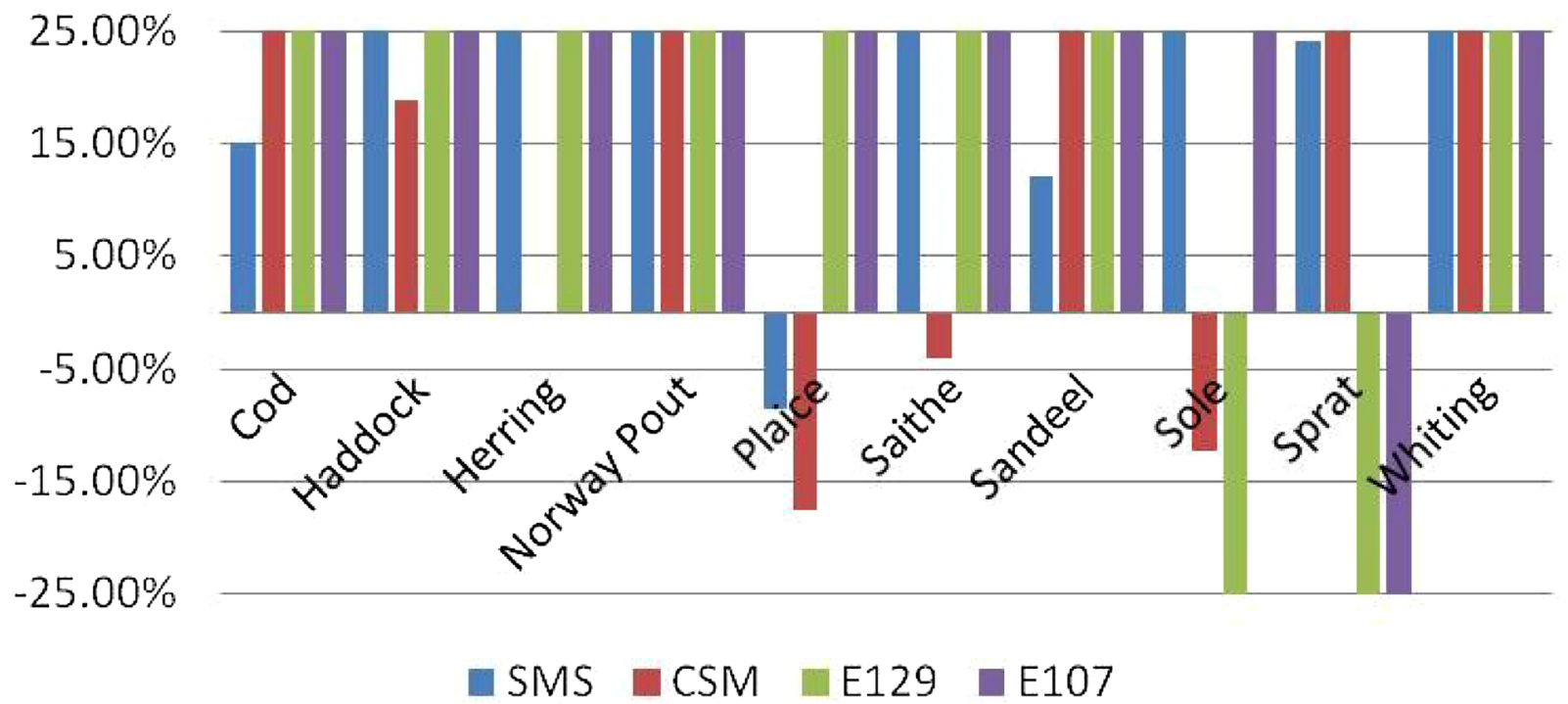

Fig. 7. Percentage change in fishing mortality rate of each North Sea species required to achieve the constrained maximization of their combined yield for each model.

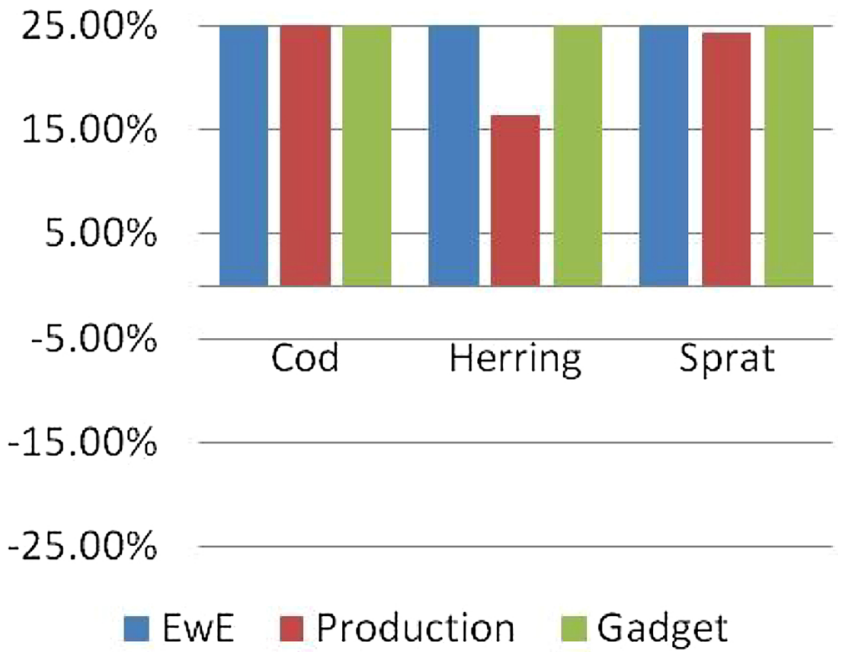

Fig. 8. Percentage change in fishing mortality rate of each Baltic Sea species required to achieve the constrained maximization of their combined yield, for each model.

\subsection{Model consistency in constrained yield maximization within areas}

For all three areas studied, the results of the constrained maximizations of the combined yield of all species show that models most commonly indicate this objective would be met at higher levels of fishing mortality rate for many of the species. Since in essence multispecies models seek to describe the feedbacks between species this result is not surprising. For example, when a predator species is fished at high levels in a multispecies model, its prey increases, leading to more available food and increased growth of the predator (depending on model structure). Indeed, multispecies models are often more optimistic about the fishing mortalities that would maximise yield than single species models (Walters et al., 1997).

A second aspect is that many fisheries considered in this study are now fished near to their single species Fmax levels (Fernandes and Cook, 2013), which contributed to increased stock sizes. Larger stocks sizes may increase predation on prey, increase cannibalism and decrease growth of target species, which are the feedback mechanisms that multispecies models seek to describe. These feedbacks would in many cases serve to make the single species estimates of Fmax, which are currently used as the basis of management, too low. Thus, it confirms the expectation that multispecies models that include these feedbacks in various forms should on the whole advocate higher than current levels of fishing mortality rate to achieve maximum total yields in our study systems. This seems to be the case in the North Sea, Baltic Sea and in Icelandic waters where the overall yield maximisation leads to the yield of most stocks increasing. In the North Sea only the yield of saithe declines in the SMS model, in CSM only the yield of cod declines marginally, in E129 only the yield of sole and sprat decline and in E107 only the yield of plaice and sprat decline to achieve the overall maximum. In the Baltic Sea only the yield of cod declines in the EwE and Gadget model. In Icelandic waters only the yield of cod and saithe decline in the Atlantis model and in EwE only the demersalcommercial group of species and haddock decline to achieve the overall constrained maximum yield.

Third, total maximum yields may be dominated by more productive, lower trophic level species. Thus, in such systems where fisheries target species across multiple trophic levels, models may advise to increase fishing mortalities of top predators not necessarily because those predators yield will be increased, but to decrease their biomass, and thereby predation on the productive forage fish. This is the case for example for the Baltic Sea Gadget and EwE models, which both predict decreased cod yields with increased cod fishing but still suggest an increased cod fishing mortality rate to achieve maximum total yields.

\subsection{Future directions}

All fisheries models, both single and multispecies, provide a way to forecast the outcomes of various hypotheses about the main drivers of the dynamics of fish stocks. In the present study we contrast outcomes of 9 multispecies models applied in three different areas. These range from bottom up models such as EwE and Atlantis to top down models such as SMS, CSM and Gadget. It is clear from the results and discussion that their detailed predictions vary considerably within an area. Clearly, it follows that ways to test the different assumptions they embody is an urgent need. As part of this it will probably be necessary to examine the influence of and evidence for assumptions made by different models such as the existence and form of the stock recruitment relationships adopted or assumptions about the form of predation or growth relationships. It should also be noted that different plausible parameterization of such assumptions would also likely affect the predicted outcomes of each model were it viewed in isolation. Thus, differences between models arise not only due to different mathematical formulations of natural processes but also due to parameter 


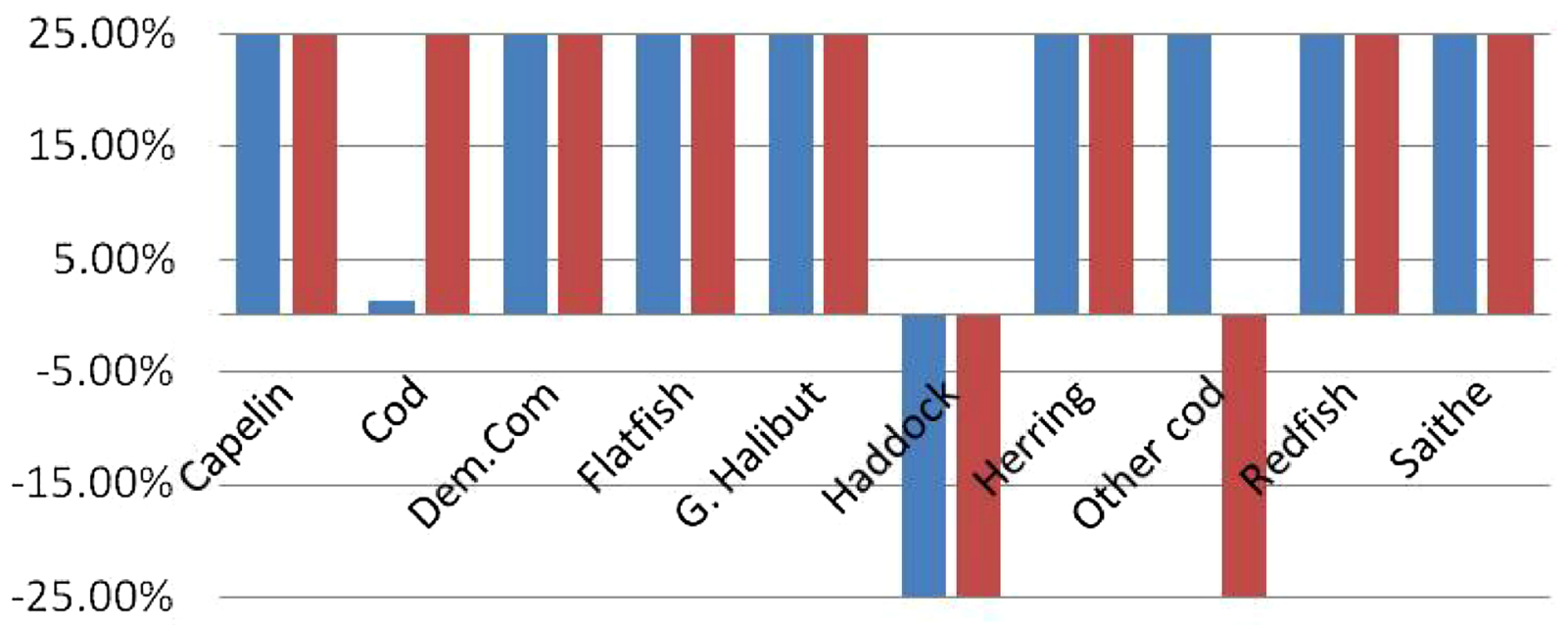

\section{Atlantis $\square$ EwE}

Fig. 9. Percentage change in fishing mortality rate of each Icelandic Waters species required to achieve the constrained maximization of their combined yield, for both models.

uncertainty. This suggests tests of the sensitivity of the approximate Jacobian matrices to parameter estimates could be a useful step. This would allow a study of both the differences we observe between models due to model structure and to likely variations within models due to parameterization choices.

How to test the different hypothesis embodied in multispecies models is a question for future research. One interesting idea might be to ask how any model would be expected to impact the results of single species models. For example, specific assumptions about predation mortality might perhaps be expected to induce characteristic patterns of correlation between lagged predator recruitment and prey recruitment.

Despite large uncertainties and differences between the results of multispecies models, it is important to note their essential role in fisheries science, both to make EBFM operational and also to support current stock assessments (Pope, 1991; ICES, 2018). So in the longer run, the development of a framework to test the hypotheses represented by various models will be a necessary step for their improved operational use. However, since it may not be possible to find a 'best formulation' for all modelled processes, it follows that differences between models may continue to form the major source of uncertainty in predictions. Hence both now and in the future it would be wise to have several models for an area, and not to put too much trust in any particular model. It will also be wise to use models to indicate the broad directions of change in fishing mortality that are required to achieve an objective rather than to trust their detailed predictions.

Their ability to indicate the broad directions of change in fishing mortality that would be required to move towards particular objectives is a strength of the Jacobian matrix approach to comparing models. The Jacobian Matrix itself is a succinct descriptor of how a model predicts how each species component is affected by small changes to its own or other species fishing mortality rates. Moreover, in the near field (it is suggested the near field should be regarded as fishing mortality changes of no more than $\pm 25 \%$ ) it can be used to approximate how best a specific objectives could be met. In this paper, which is concerned with comparing different models, such investigations are confined to a consideration of how best the long term combined yield of all included species could be maximised within the near field. However, with suitable social and economic information added to the model there is no obvious limit to the objectives that could be considered. For examples of such Jacobian matrix based approximations to other objectives see Pope (2018).

Clearly the Jacobian matrix is a useful approach to comparing different multispecies fisheries model or indeed of investigating the behaviour and sensitivity of an individual model but as noted in the introduction it is by no means the only approach. By their nature multispecies fisheries models generate large amounts of output in a bewildering range of variables and "the wood is typically difficult to see from the trees". Thus to ease comprehension we believe that any investigation of a models behaviour is best confined to only one or two simple questions and must use a clear method of analysis of model results to address these questions. While the Jacobian matrix approach seems an excellent analysis for investigating the near field responses of long term yield or biomass of models to relative changes in mortality rate it is clear that other analytical approaches will be needed to compare for example the ecosystem structure and functions that particular models propose or to consider the trajectories that stocks might follow on the path to any long term steady state.

\section{Acknowledgements}

The research leading to these results has received funding from the European Union's Seventh Framework Programme Project MareFrame: Co-creating Ecosystem-based Fisheries Management Solutions under Grant Agreement no. 613571, from the European Commission's Horizon 2020 Research and Innovation Programme under Grant Agreement No. 634495 for the project Science, Technology, and Society Initiative to minimize Unwanted Catches in European Fisheries (MINOUW) and from DEFRA project number MA 016A. Supercomputing support for the LeMans model was provided by HPC at the University of East Anglia. Personal thanks are due to Morton Vinther for providing customized outputs of the SMS model.

\section{Appendix A. Supplementary data}

Supplementary material related to this article can be found, in the online version, at doi:https://doi.org/10.1016/j.fishres.2018.08.011.

\section{References}

Audzijonyte, A., Gorton, R., Kaplan, I., Fulton, E.A., 2017a. Atlantis User's Guide Part I: General Overview, Physics \& Ecology. CSIRO, Hobart, Australia.

Audzijonyte, A., Gorton, R., Kaplan, I., Fulton, E.A., 2017b. Atlantis User's Guide Part II: Socio-Economics. CSIRO, Hobart, Australia.

Bauer, B., Meier, H.E.M., Casini, M., Hoff, A., Margoński, P., Orio, A., Saraiva, S., Steenbeek, J., Tomczak, M.T., 2018. Reducing eutrophication increases spatial extent 
of communities supporting commercial fisheries: a model case study. ICES J. Mar. Sci. https://doi.org/10.1093/icesjms/fsy003.

Casini, M., Kornilovs, G., Cardinale, M., Möllmann, C., Grygiel, W., Jonsson, P., Raid, T., Flinkman, J., Feldman, V., 2011. Spatial and temporal density dependence regulates the condition of central Baltic Sea clupeids: compelling evidence using an extensive international acoustic survey. Popul. Ecol. 53, 511-523. https://doi.org/10.1007/ s10144-011-0269-2.

Christensen, V., Pauly, D., 1992. Ecopath-II - a software for balancing steady state ecosystem models and calculating network characteristics. Ecol. Modell. 61 (3-4), 169-185 61, 169-185.

Christensen, V., Walters, C.J., 2004. Ecopath with Ecosim: methods, capabilities and limitations. Ecol. Modell. 172, 109-139.

Collie, J.S., Gislason, H., Vinther, M., 2003. Using AMOEBAs to display multispecies, multifleet fisheries advice. ICES J. Mar. Sci. 60, 709-720. https://doi.org/10.1016/ S1054-3139(03)00042-0.

Essington, T.E., 2004. Getting the right answer from the wrong model: evaluating the sensitivity of multispecies fisheries advice to uncertain species interactions. Bull. Mar. Sci. 74, 563-581.

Fernandes, P.G., Cook, R.M., 2013. Reversal of fish stock decline in the Northeast Atlantic. Curr. Biol. 23, 1432-1437. https://doi.org/10.1016/j.cub.2013.06.016.

Forrest, R.E., Savina, M., Fulton, E.A., Pitcher, T.J., 2015. Do marine ecosystem models give consistent policy evaluations? A comparison of Atlantis and Ecosim. Fish. Res. 167, 293-312. https://doi.org/10.1016/J.Fishres.2015.03.010.

Fulton, E.A., Smith, A.D.M., 2004. Lessons learnt from a comparison of three ecosystem models for Port Phillip Bay, Australia. Afr. J. Mar. Sci. 26, 219-243. https://doi.org/ 10.2989/18142320409504059.

Fulton, E.A., Link, J.S., Kaplan, I.C., Savina-Rolland, M., Johnson, P., Ainsworth, C., Horne, P., Gorton, R., Gamble, R., Smith, A.D.M., Smith, D.C., 2011. Lessons in modelling and management of marine ecosystems: the Atlantis experience. Fish Fish. 12, 171-188.

Gårdmark, A., Lindegren, M., Neuenfeldt, S., Blenckner, T., Heikinheimo, O., MüllerKarulis, B., Niiranen, S., Tomczak, M.T., Aro, E., Wikström, A., Möllmann, C., 2013. Biological ensemble modeling to evaluate potential futures of living marine resources. Ecol. Appl. 23, 742-754. https://doi.org/10.1890/12-0267.1.

Hall, S.J., Collie, J.S., Duplisea, D.E., Jennings, S., Bravington, M., Link, J., 2006. A length-based multispecies model for evaluating community responses to fishing. Can. J. Fish. Aquat. Sci. 63, 1344-1359. https://doi.org/10.1139/f06-039.

Hilborn, R., 2010. Pretty Good Yield and exploited fishes. Mar. Policy 34, 193-196.

Hill, S.L., Watters, G.M., Punt, A.E., McAllister, M.K., Quéré, C.L., Turner, J., 2007. Model uncertainty in the ecosystem approach to fisheries. Fish Fish. 8, 315-336. https://doi. org/10.1111/j.1467-2979.2007.00257.x.

Horbowy, J., 1996. The dynamics of Baltic fish stocks on the basis of a multispecies stockproduction model. Can. J. Fish. Aquat. Sci. 53, 2115-2125. https://doi.org/10.1139/ f96-128.

Horbowy, J., 2005. The dynamics of Baltic fish stocks based on a multispecies stock production model. J. Appl. Ichthyol. 21, 198-204. https://doi.org/10.1111/j.14390426.2005.00596.x.

Horbowy, J., Swinder, M., 1989. Growth of Baltic sprat in relation to stock density and food biomass. Rapp. P.-v. Reun. Cons. Int. Explor. Mer. 190, 102-104.

ICES, 1989. Report of the Multispecies Assessment Working Group, Copenhagen 7-16 June 1989. ICES CM1989/Assess:20.

ICES, 2014a. Interim Report of the Working Group on Multispecies Assessment Methods (WGSAM). 20-24 October 2014, London, UK. ICES CM 2014/SSGSUE:11. 104 pp...

ICES, 2014b. Report of the Study Group on Spatial Analyses for the Baltic Sea (SGSPATIAL). ICES CM 2014/SSGRSP:08..

ICES, 2016a. Report of the Baltic International Fish Survey Working Group (WGBIFS). ICES CM 2016/SSGIEOM:07, 21-25..

ICES, 2016b. Report of the Working Group on Multispecies Assessment Methods (WGSAM). 10-14 October 2016, Reykjavik, Iceland. ICES C. 2016/SSGEPI21 94 pp..

ICES, 2016c. Report of the Baltic Fisheries Assessment Working Group (WGBFAS). ICES CM 2016/ACOM:11, doi: ICES CM 2016/ACOM:11.

ICES, 2018. Interim Report of the Working Group on Multispecies Assessment Methods (WGSAM). 16-20 October 2017, San Sebastian, Spain. ICES CM 2017/SSGEPI:20 395 pp..

Jones, R., 1978. Estimates of the food consumption of haddock (Melanogrammus aeglefinus) and cod (Gadus morhua). J. Cons. Int. Explor. Mer 38, 18-27.

Kaplan, I.C., Brown, C.J., Fulton, E.A., Gray, I.A., Field, J.C., Smith, A.D.M., 2013. Impacts of depleting forage species in the California current. Environ. Conserv. 40, 380-393. https://doi.org/10.1017/S0376892913000052.

Kempf, A., Mumford, J., Levontin, P., Leach, A., Hoff, A., Hamon, K.G., Bartelings, H., Vinther, M., Stäbler, M., Poos, J.J., Smout, S., Frost, H., van den Burg, S., Ulrich, C., Rindorf, A., 2016. The MSY concept in a multi-objective fisheries environment - lessons from the North Sea. Mar. Policy 69, 146-158. https://doi.org/10.1016/J. MARPOL.2016.04.012.

Kulatska, N., Neuenfeldt, S., Beier, U., Elvarsson, B., Wennhage, H., Stefansson, G., Bartolino, V., 2018. Understanding ontogenetic and temporal variability of Eastern Baltic cod diet using a multispecies model and stomach data. J. Fish. Res VSI: Advancing EBFM.

Lewy, P., Vinther, M., 2004. A Stochastic Age-Length Structured Multi-species Model Applied to North Sea Stocks. ICES CM, 2004. http://www.ices.dk/sites/pub/CM \%20Doccuments/2004/FF/FF2004.pdf.

Nielsen, J.R., Thunberg, E., Holland, D.S., Schmidt, J.O., Fulton, E.A., Bastardie, F., Punt, A.E., Allen, I., Bartelings, H., Bertignac, M., Bethke, E., Bossier, S., Buckworth, R., Carpenter, G., Christensen, A., Christensen, V., Da-Rocha, J.M., Deng, R., Dichmont, C., Doering, R., Esteban, A., Fernandes, J.A., Frost, H., Garcia, D., Gasche, L., Gascuel, D., Gourguet, S., Groeneveld, R.A., Guillén, J., Guyader, O., Hamon, K.G., Hoff, A., Horbowy, J., Hutton, T., Lehuta, S., Little, L.R., Lleonart, J., Macher, C., Mackinson, S., Mahevas, S., Marchal, P., Mato-Amboage, R., Mapstone, B., Maynou, F., Merzéréaud, M., Palacz, A., Pascoe, S., Paulrud, A., Plaganyi, E., Prellezo, R., Putten, E.Ivan, Quaas, M., Ravn-Jonsen, L., Sanchez, S., Simons, S., Thébaud, O., Tomczak, M.T., Ulrich, C., Dijk, Dvan, Vermard, Y., Voss, R., Waldo, S., 2017. Integrated ecological-economic fisheries models-evaluation, review and challenges for implementation. Fish Fish. 19, 1-29. https://doi.org/10.1111/faf.12232.

Pauly, D., Christensen, V., Walters, C., 2000. Ecopath, ecosim, and ecospace as tools for evaluating ecosystem impact of fisheries. ICES J. Mar. Sci. 57, 697-706.

Plaganyi, E.E., 2007. Models for an ecosystem approach to fisheries. Fisheries Technical Paper (FAO). Fisheries Technical Paper, No. 477. Rome, Italy.

Pope, J.G., 1991. The ICES multispecies assessment working group: evolution, insights, and future problems. ICES Mar. Sci. Symp. 193, 22e33.

Pope, J.G., 2018. T-ONS a swift transportable and user friendly integrative model of the North Sea for EBFM decision support. J. Fish. Res VSI: Advancing EBFM.

Pope, J.G., Rice, J.C., Daan, N., Jennings, S., Gislason, H., 2006. Modelling an exploited marine fish community with 15 parameters - results from a simple size-based model. ICES J. Mar. Sci. 63, 1029-1044.

Smith, A.D.M., Brown, C.J., Bulman, C.M., Fulton, E.A., Johnson, P., Kaplan, I.C., LozanoMontes, H., Mackinson, S., Marzloff, M., Shannon, L.J., Shin, Y.-J., Tam, J., 2011. Impacts of fishing low-trophic level species on marine ecosystems. Science 80 (333) 1147 LP-1150.

Smith, M.D., Fulton, E.A., Day, R.W., Shannon, L.J., Shin, Y.-J., 2015. Ecosystem modelling in the southern Benguela: comparisons of Atlantis, Ecopath with Ecosim, and OSMOSE under fishing scenarios. Afr. J. Mar. Sci. 37, 65-78. https://doi.org/10. 2989/1814232X.2015.1013501.

STECF, 2014. Evaluation of Fishing Effort Regimes in European Waters (STECF-14-12). Publications Office of the European Union, Luxembourg EUR 26812 EN, JRC 91542, 480 pp.

Sturludottir, E., Desjardins, C., Elvarsson, B., Fulton, E.A., Gorton, R., Logemann, K., Stefansson, G., 2018. End-to-end model of Icelandic waters using the Atlantis framework: exploring system dynamics and model reliability. Fish. Res. 207, 9-24 (this issue).

Thorpe, R.B., LeQuesne, W.J.F., Luxford, F., Collie, J.S., Jennings, S., 2015. Evaluation and management implications of uncertainty in a multispecies size-structured model of population and community responses to fishing. Methods Ecol. Evol. 6, 49-58. https://doi.org/10.1111/2041-210X.12292.

Thorpe, R.B., Dolder, P.J., Reeves, S., Robinson, P., Jennings, S., 2016. Assessing fishery and ecological consequences of alternate management options for multispecies fisheries. ICES J. Mar. Sci. 73, 1503-1512.

Thorpe, R.B., Jennings, S., Dolder, P., 2017. Risks and benefits of catching pretty good yield in multispecies mixed fisheries. ICES J. Mar. Sci. 74, 2097-2106.

Tittensor, D.P., Eddy, T.D., Lotze, H.K., Galbraith, E.D., Cheung, W., Barange, M., Blanchard, J.L., Bopp, L., Bryndum-Buchholz, A., Büchner, M., Bulman, C., Carozza, D.A., Christensen, V., Coll, M., Dunne, J.P., Fernandes, J.A., Fulton, E.A., Hobday, A.J., Huber, V., Jennings, S., Jones, M., Lehodey, P., Link, J.S., Mackinson, S., Maury, O., Niiranen, S., Oliveros-Ramos, R., Roy, T., Schewe, J., Shin, Y.-J., Silva, T., Stock, C.A., Steenbeek, J., Underwood, P.J., Volkholz, J., Watson, J.R., Walker, N.D., 2018. A protocol for the intercomparison of marine fishery and ecosystem models: Fish-MIP v1.0. Geosci. Model Dev. 11, 1421-1442. https://doi.org/10.5194/gmd-11-14212018.

Walters, C.J., Christensen, V., Pauly, D., 1997. Structuring dynamic models of exploited ecosystems from trophic mass-balance assessments. Rev. Fish Biol. Fish. 7, 139-172.

Walters, C., Pauly, D., Christensen, V., Kitchell, J.F., 2000. Representing density dependent consequences of life history strategies in aquatic ecosystems: ecosim II. Ecosystems 3, 70-83.

Whipple, S.J., Link, J.S., Garrison, L.P., Fogarty, M.J., 2000. Models of predation and fishing mortality in aquatic ecosystems. Fish Fish. 1, 22-40. https://doi.org/10. 1046/j.1467-2979.2000.00007.x. 